\title{
Pueblo mártir. Reflexión sobre el "pueblo crucificado"
}

\section{Rolando Alvarado, Centro de Reflexión Teológica, San Salvador.}

El lítulo de este escrito lo he tomado prestado del obispo brasileño Pedro Casaldáliga'. Por dos razones. En primer lugar, porque lo que dice del pueblo brasileño podemos legítimamente extenderlo a otros pueblos del continente americano y a sociedades de otras latitudes. En efecto, morir por hambre y desnutrición, ser despojados de la tierra o de la posibilidad de un techo mínimamente digno, padecer indefensamente conflictos militares y matanzas provocadas por odios ancestrales, subsistir cotidianamente en la degradación y la humillación - sea por prostitución, por ser dado en pago laboral de esclavitud a causa de deudas contraidas por los padres o por tener que trabajar sin ningún tipo de prestaciones sociales - son situaciones que padecen miles de millones de seres humanos en nuestro planeta.

Prácticamente, en esas realidades viven dos tercios de sus recién estrenados seis mil millones. Visto en su conjunto, son pocos los habitantes de nuestro mundo que han escapado, estructuralmente, a ser maltratados y vejados. A muchísimos de ellos los han dejado "como a un Cristo", como decía Ignacio Ellacuría, usando castellano castizo. Para el obispo poeta, esa situación de exterminio, muchas veces ruidoso y casi siempre silencioso, que han sufrido las comunidades indígenas brasileñas ha sido la de un claro y cruel martirio. Al constatar, repetida y multiplicadamente, esa situación ayer y hoy en tantos otros pueblos podemos considerarlos también como pueblos crucificados.

Ahora bien, y aquí entramos en la seguna razón para el préstamo del título. ¿Puede hablarse con propiedad teológica de "pueblos mártires"? ¿Puede afir-

I. P. Casaldáliga, «Los indios «crucifiçados». Un caso anónimo de martirio colectivo», Conciliwn 183 (1983) 383-389. 
marse que existen "martirios colectivos"? ¿O nos estamos dejando llevar por la indignación y la retórica? No hay que olvidar -se podría objetar- que Casaldáliga es un pastor poela y que la poesía, siendo imprescindible para poner en palabra vivencias inmediatas, emociones intensas, y devolver al lenguaje su fuerza y belleza originarias, no es muy cercana al rigor que busca alcanzar el concepto y la argumentación teológicas. Puede ser que haya aquf algo de razón, pero tampoco deja de resultar curioso que para el poeta Casaldáliga su têrmino "pueblo mártir" sea equivalente al concepto de "pueblo crucificado", creado, como es sabido, por el teólogo Ignacio Ellacuría. Este disfrutaba y apreciaba la poesía - como lo muestra su admiración personal por el poeta Angel Martínez y las reflexiones sobre la poesía de este $^{2}$ y de otros conocidos poetas ${ }^{3}$-, pero tendía claramente a la precisión técnica y al rigor conceptual.

En cualquier caso, la convergencia de significado entre ambos conceptos -el del poeta y el del teólogo- orienta y delimita lo que aquí nos interesa reflexionar. ¿En qué consiste el carácter martirial del pueblo crucificado? A la luz de la fe cristiana, ipuede considerarse mártir - y en qué sentido- a esa ingente masa de humanidad hambrienta, desarraigada y en continua búsqueda de refugios, víctima de catástrofes naturales - terremolos, crupciones volcánicas e inundaciones-, machacada por múltiples y serios traumas psicológicos y por graves y terribles injusticias sociales e históricas? ¿En esa situación de postración de lantos miles de millones de seres humanos es posible percibir y perfilar un modo especílico de martirio? Intentar dar respuesta a estas preguntas será nuesıra contribución a este número monográfico sobre el martirio.

\section{Trayectoria del concepto "el pueblo crucificado" en I. Ellacuría}

A juzgar por lo que consta en sus escritos, la primera vez que Ellacuría utilizó explícitamente la categoría "pueblo cruficado" fue en 1978, en un artículo que claboró para una obra colectiva sobre Cruz y resurrección ${ }^{4}$. De ese artículo hay ahora dos versiones que difieren entre sí, aunque sólo sea en la introducción. Acabamos de mencionar dónde apareció la primera versión. La segunda apareció en 1983, cuando Ellacuría reunió varios escritos suyos en su libro Conversión de la Iglesia al reino de Dios'. Esta segunda versión del texto es la

2. Cfr. I. Ellacurfa, «Angel Martínez, S. J.», Escrilos filosoficos I, 1996, pp.117-124; "Angel Martíncz, poeta esencial», op. cit., pp.127-195; «Correspondencia con Angel Martínez», op. cit., pp. 197-213.

3. Cfr. «Religiosidad pluriforme: Carducci, Maragall, Rilke», op. cit.. pp. 535-543.

4. Me refiero a: Varios, Crizz y resurrección (México, 1978). El artículo de Ellacuria se encuentra en las pp.49-82.

5. Conversión de la Iglesia al reino de Dios. Para anunciarlo y realizarlo en la hisio-

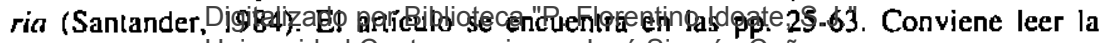
Universidad Centroamericana José Simeón Cañas 
que sc ha impreso posteriormente en varias ocasiones.

El ligero cambio en la introducción se debe simplemente a la diversa finalidad que cumplía el artículo en los dos libros. En la primera versión, el interés era aclarar si la pasión y muerte de Jesucristo es algo que pertenece al pasado o si significa también hoy una buena noticia para nuestras vidas y una ayuda concreta para resolver, nuestros propios problemas y afanes. La tesis que sostiene Ellacuría es que la pasión y muerte de Jesús continúan operando en nuestro favor; es decir, nos siguen trayendo la salvación, ahora a través de la pasión y muerte del pueblo crucificado.

En la segunda versión del artículo ${ }^{6}$, el interés no es ya soteriológico, sino eclesiológico; es decir, el autor considera que para comprender auténticamente y en su totalidad lo que es el pueblo de Dios es imprescindible tomarlo como pueblo de Dios crucificado. En el Vaticano II la Iglesia se había comprendido a sí misma como pueblo de Dios. Ella lo es, en efecto, quizás es su momento pleno y verdadero, pero Ellacuría quiere recalcar que la Iglesia no es todo el pueblo de Dios, que éste no se reduce y se agota en ella. Entre Iglesia y pueblo de Dios existe, pues, una relación esencial, pero aquél es una realidad más amplia al interior de la cual la Iglesia encuentra su morada, su identidad y su misión. Es delante de ese pueblo - una de cuyas notas características es la de estar siendo crucificado- que la Iglesia debe situarse y llevar a cabo su misión de bajarlo de la cruz, aun teniendo que pagar el precio de acabar ella misma amenazada, perseguida y hasta condenada a muerte - como de hecho ha sucedido en diversos lugares y en distintos momentos de la historia.

\subsection{La experiencia personal ante el pueblo crucificado}

Antes de esclarecer el significado del concepto conviene explicitar dónde se halla su ralz más honda. Para Ellacuría esa raíz no se encuentra en la necesidad de solucionar un problema teórico, por muy decisivo que éste sea o lo parezca, ni tampoco se encuentra en el deseo de elaborar una nueva categoría teológica, por muy original y certera que resulte. A mi modo de ver, lo que impulsa a Ellacuría a hablar de "pueblo crucificado" es una experiencia personal espiritual. Es la vivencia cristiana de interiorizar creyentemente el dolor y los padecimien-

introducción que antecede a los tres textos reunidos para conformar la primera parte del libro, titulada «Iglesia y pueblo de Dios».

6. Para captar toda la compleja y decisiva relación que existe — según Ellacurfa- entre el pueblo de Dios crucificado y la Iglesia como realidad institucional y carismática convendra leer, además del artículo «Pueblo crucificado», otros tres: «La Iglesia que

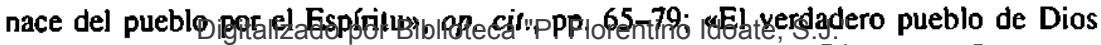

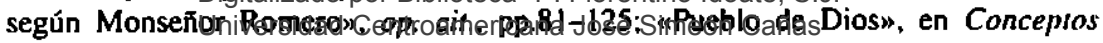
fundamentales de pastoral (Madrid, 1983), pp. 840-855. 
los del mundo como dolores y padecimientos de Dios mismo. Los sufrimientos y agonias de tantos millones de seres humanos no son un hecho ajeno ni periférico a la fe genuinamente cristiana, puesto que son las angustias del propio Dios.

Visto desde Dios, a la luz de la revelación bíblica aparece con diafanidad que el Señor ha querido, libre y bondadosamente, hacer suyos esos dolores, de modo que quienes queramos - y digamos- creer en el Dios cristiano tenemos que abrinos a interiorizarlos como la prolongación de su padecimiento, un padecimiento injusto y que sólo adquiere sentido en el momento en que el Señor lo asume para, desde su interior, su crudeza y su penumbra, alcanzarnos la redención (Mı 25, 31-46). No asumir las tragedias y clamores del mundo de esa manera y con esa hondura, sería cegarnos a la presencia de Dios en nuestro mundo, cerramos a su manifestación. Sería negarnos a que, desde esos padecimientos y manteniéndolos gracias a la fortaleza de su Espíritu, Dios nos libere de ellos, quitándoles la última palabra que pretenden dictar sobre nuestras vulnerables vidas y nuestras frágilas historias.

Visto desde los seres humanos, no asumir y enfrentar así los incontables clamores y dolores en que nos movemos, podría llevarnos a la convicción de que este valle de lágrimas no tiene realmente salida, que la historia humana está abocada al fracaso y que toda la humanidad, en su diversidad de pueblos y culturas, tiene como destino final la tristeza y la muerte. En el mejor de los casos, de lo que se trataría en eso que llamamos "saber vivir" es de ir sorteando y esquivando, como mejor podamos, esa muerte y esa tristeza.

El creyente Ignacio Ellacuría, gracias a la interiorización y al procesamiento espiritual que hace del sufrimiento, expulsa de su corazón ese ateísmo radical. El ateísmo que brota del masivo, asfixiante y ensimismante sufrimiento humano, no el ateísmo que surge de una pretendida racionalidad o el que se perfila por reacción a las incoherencias de las religiones y de las Iglesias. Dos textos pueden fungir como prueba de lo que acabamos de decir 0 , al menos, como insinuación: la matriz de lo que llamará "pueblo crucificado" está en la experiencia espiritual.

El primer texto data de 1974 , aunque fue publicado póstumamente casi veinte años más tarde, en 19917. El texto recoge unas conferencias pronunciadas sobre los Ejercicios Espirituales de san Ignacio de Loyola, en las que Ellacuría interpreta el clásico libro del místico vasco desde los pueblos del tercer mundo - hoy quizá diría del sur. En el punto sobre la cruz de Cristo, señala que esa cruz y esa pasión continúan ante nosotros. Que viendo a tantos pueblos sumergidos en la opresión, la injusticia y la desesperación, no podemos más que recono-

7. «Lectura latinoamericana de los Ejercicios Espirituales de san Ignacio», Revista Latinoamericana

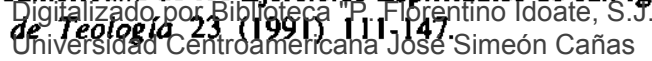


cer que, por una parte, ese dar muerte, ese crucificar, es resultado de nuestros pecados, y que, por otra, desde esa cruz del tercer mundo Dios ha querido operar nuestra salvación.

Esta función del tercer mundo en la obra salvífica no es algo que el propio tercer mundo pueda alribuirse a sí mismo, por ser un mundo más piadoso o más religioso, ni siquiera porque en él sean detectables admirables valores cristianos. El que el tercer mundo desempeñe esa función en el designio liberador de Dios sólo es reconocible al mirar a "ese tercer mundo como resultado del pecado y como víctima de él, pero también como lugar del escondimiento de Dios. Al verlo desde el pecado sitúa su realidad en una estricta historia de la salvación, y al verlo como lugar de predilección escandalosa de Dios ofrece la clave salvadora de la historia"8.

Lo que aquí nos interesa destacar es el contexto en que se describe - todavía no se conceptúa - la realidad del pueblo crucificado y su papel en la historia de la salvación. Ese contexto no son charlas o conferencias de teología sin más, sino reflexiones sobre un proceso de conversión espiritual, ideado por san Ignacio, quien, como es sabido, desea que el texto de sus Ejecicios Espirituales sea puesto en práctica, no sólo leído o aprendido. Quienes han tenido la oportunidad de "dar puntos" ignacianos, de reflexionar o escribir sobre alguna de sus meditaciones saben que todo ello es posible si esa experiencia ha sido vivida personal $y$ profundamente.

El segundo texto en que se trasluce la raíz espiritual del concepto "pueblo crucificado" es el discurso - y consta en el texto ${ }^{9}$ - que pronunció al recibir el doctorado honoris causa in Human Letsers que le concedió la Universidad de Santa Clara, Estados Unidos, en 1982. En esa oportunidad, además de agradecer el reconocimiento y respaldo personal y, sobre lodo, institucional (considera que es un espaldarazo a la tarea de la UCA en favor de la paz y la negociación, en momentos graves y diff́ciles para el país), solicita a quienes se lo han concedido que se mantenga y profundice ese impulso, y para ello no encuentra mejor motor que invitarlos a la actitud de renovación permanente que cultiva el proceso espiritual ignaciano. ¿Cómo puede la comunidad universitaria de Santa Clara, que se comprende a sí misma como una comunidad de inspiración cristiana, continuar apoyando la tarea de la comunidad universitaria de la UCA? "No me toca a mi decirles cómo lo pueden hacer. Bastaría que pusieran parte de su potencial universitario y de todo su corazón humano y cristiano ante la realidad de un mundo crucificado y se respondieran a la triple pregunta que san Ignacio de Loyola se hacía ante el paradigma y representante de todos los crucificados:

8. Ibid Digitalizado por Biblioteca "P. Florentino Idoate, S.J."

9. El discurso lue publicado en Carta a las Iglesias 22 (16-30 de junio de 1982) 11-15. 
¿qué he hecho yo por este mundo? ¿qué hago ahora por él? Y, sobre todo, ¿qué debo hacer?"'In.

\subsection{El pueblo crucificado como el actual siervo de Yahvé}

Si la rafz es espiritual, la nervatura y el significado de "pueblo crucificado" poseerá, obviamente, un contenido teórico. Es lo que el teólogo Ellacuría lleva a cabo en el artículo ya citado de 1978. Conviene observar que en su primera vcrsión hace referencia al famoso libro del teólogo luterano Jürgen Moltmann El Dios crucificado, publicado en alemán en 1972 y en castellano en 1975. El objetivo de Ellacuría no es replicar o responder al libro de Moltmann, sino, en cierto sentido, prolongarlo, mostrando que ese Dios crucificado continúa siéndolo en su pueblo, que el Dios crucificado es el Dios de los crucificados, porque El ha querido que sean ellos los continuadores de su intención y obrar salvíficos.

La cruz de ayer - la de Jesús de Nazaret- y de la hoy - la del pueblo crucificado-, cristianamente entendidas, no son idénticas, pero tampoco son distintas. La vida y la muerte de Jesús, y la salvación que ellas han hecho posible y nos han alcanzado, son únicas, pues en ellas no ha ocurrido algo que posee el mismo valor que cualquier orra muerte, sino que en esa vida y en esa muerte ha ocurrido algo que supone la presencia definitiva de Dios entre los hombres. Ahora bien, "la unicidad de Jesús no está en su separación de la humanidad, sino en el carácter definitivo de su persona y en la omnipresencia salvífica que le compete"'. Es en esta definitividad donde —en mi opinión- está la clave de la solución. Por ser definitiva, su persona no debe comprenderse como desaparecida históricamente, como ausente sin más de la historia. El Señor, según Mateo 25. 31-46 - texto al que acude Ellacuría para probarlo-, ha elegido sus representantes, se ha identificado con esa masa de hambrientos que piden pan, de forasteros que solicitan ser acogidos, de desnudos que necesitan ser vestidos, de presos que anhelan libertad, etc. Ellos son los "vicarios de Cristo", en la espléndida formulación de J. 1. González Faus. Ellos son quienes, por su condición, juzgan —nos están juzgando ya- de la veracidad de nuestra fe y de la veracidad de nuestro seguimiento. Gracias a esa real identificación, el Señor calibrará la realidad -y no su intencionalidad- de nuestro vivir cristiano.

Y porque la salvación que el Señor nos ha procurado es definitiva y omnipresente, por ello tiene sus continuadores históricos. A través de sus vicarios sigue bregando y batallando por nuestra salvación. Este hecho, el que los crucificados sean los portadores de nuestra salvación es más difícil de aceptar que el

10. Ibid., p. 14.

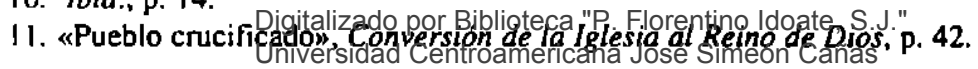


que sus sufrimientos pongan a prueba nuestra fe, nuestra esperanza y nuestro amor a Dios y a los hombres, lo cual, de una u otra manera, siempre ha estado presente en la teología y en la predicación cristianas. Pero que sean ellos, a quienes samaritanamente buscamos ayudar, quienes nos sanen de las enfermedades en que nos sumerge el pecado es algo que para Ellacuría necesilaba ser afirmado y justificado teológicamente. Para ello acude a la figura del Siervo de Yahvé (Is $42,1-7 ; 49,1-6 ; 50,4-9 ; 52,13-53,12$ ), utilizada por las primeras comunidades cristianas para explicarse el significado salvífico de Jesús, y la que nos sirve hoy a nosotros para encontrar un valor soteriológico a la muerte injusta, cruel e inmerecida de tantas personas, y al mar de padecimientos en que se desenvuelven sus desgarradas y fracturadas vidas.

Jesucristo es el autor de nuestra salvación. Y la Iglesia, tal como dice el Vaticano II, es el sacramento de esa salvación. ¿Qué hay entre ambos? Ahí sitúa Ellacuría a los desechados y des-hechos de nuestra historia. Es el pueblo crucificado, en su propia condición desfigurada y abatida, quien continúa y prolonga esa salvación por propia decisión del Señor, cuya autoría ni se discute ni se sustituye. El pueblo crucificado salva en la medida en que nos interpela continuamente a cambiar de dirección personal y de rumbo histórico. Se constituye en principio universal de la salvación, en una llamada permanente a la conversión personal e histórica: "Esta llamada a la conversión es una llamada a la salvación y a la verdadera felicidad de aquellos que buscan en la riqueza, en el poder, en el bienestar las raíces más profundas de la seguridad y de la dicha humanas"'2. Es la llamada que la Iglesia escucha, recibe en su interior, la celebra y la anuncia exteriormente a todos los pueblos y a todos los hombres, la sacramentaliza históricamente mostrando cuál es el verdadero camino de la felicidad y cómo transitar por él ${ }^{13}$.

\section{El carácter martirial del pueblo crucilicado}

Hemos analizado la raíz experiencial y el significado conceptual que atribuyó Ellacuría al pueblo crucificado, pero no hemos analizado todavía su carácter martirial -si es que lo tiene. Tratemos de analizarlo.

\subsection{Planteamiento del problema}

Desde el principio me parece importante reconocer dos cosas. La primera es que Ellacuría no se plantea explícitamente el problema, al menos no en los términos en que aquí lo planteamos. Lo que a él le interesa - tal como lo

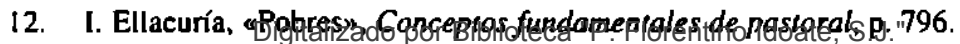

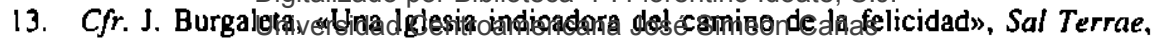
Tomo 84/8 (1996) 659-677. 
acabamos de exponer- es el valor soteriológico de las mayorías oprimidas, excluidas y abatidas; no su posible carácter martirial. Ahora bien, el mismo Ellacuría tiende puentes intelectuales entre su preocupación (capacidad soteriológica) y la nuestra (status martirial). A veces, insinúa directamente algún tipo de solución. Veámoslo.

Otto Semmelroth, en su jugoso y profundo artículo sobre lo que se entiende por martirio en el cristianismo ${ }^{14}$, destaca los diversos ángulos desde los que se puede abordar la figura del mártir. Etimológica y teológicamente, el martirio es más amplio que el "bautismo de sangre". El mártir es aquel cuya vida y cuya muerte se asemejan a la vida y a la muerte de Jesucristo. Aquel cuyo testimonio -mártir, como es sabido, significa testigo- resulta eficaz ante los hombres porque, al entregar sin resistencia la vida, al desgastarla generosamente y llegar a padecer pacíficamente la muerte, anida en su muerte toda una virtualidad redentora. Para entendernos: un mártir participa de la misión salvadora de Cris10, es incorporado a la "nube de testigos" por la afinidad de vida y de destino que ha tenido con la vida $y$ el destino de Jesucristo. $Y$ de ello resulta que su muerte adquiere potencialidad salvifica.

No cualquier pasión y cualquier muerte son pasión y muerte martiriales, sino que, para serlo, ambas tienen que asemejarse a las del Señor. Pues bien, Ellacuría - tal como lo hemos apuntado- entiende que la pasión y la muerte del pueblo crucificado no sólo se parecen a las de Jesús de Nazaret, sino que son su real e histórica continuación, y por ser esa continuación son portadoras de la salvación. Aunque lo que Ellacuría tenía en el punto de mira era mostrar el lugar que ocupa el pueblo crucificado en la historia de la salvación, al ser la función de éste una de las funciones que se atribuyen al martirio -incidir en nuestra salvación-, de manera indirecta está afirmando la existencia de un martirio de las mayorías. El valor soteriológico del pueblo crucificado serla lo que posibilita captar el rostro martirial de los vencidos de la historia.

Pero Ellacuría hace también una afirmación que insinúa más explícitamente la dimensión martirial. En sus escritos teológicos reflexiona en varias ocasiones sobre la persecución que desemboca en el martirio. Y llega a distinguir entre una persecución estructural, básica y mayoritaria, y otra que proviene de una decisión consciente y libre de quienes en el seguimiento explícito o anónimo (Rahner) de Jesucristo, batallando por el reino de Dios, se encuentran, al igual que $\mathrm{el}$, con la muerte y el martirio. Reproduzcamos dos textos. El primero es breve: "Ante todo, se da la persecución del pueblo, una persecución que es radicalmente la de la opresión y que después se convierte en represión, cuando el pueblo ya concientizado y organizado lucha por su liberación"'s. El tenor de

14. Cfr. Otto Semmelrolh, "Martirio», Sacramentum Mundi IV, Barcelona (1973) cc. 455-460.

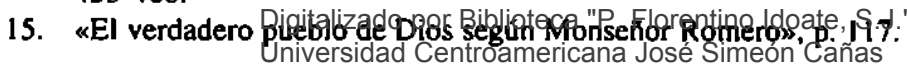


este primer texto explicita ya la distinción que hemos señalado, pero es el segundo texto el que para nuestro tema resulta decisivo. Aunque sea un poco largo vale la pena transcribirlo:

La persecución tiene carácter teologal, y no meramente carácter ético-político, cuando se desala contra el pueblo de Dios que busca la instauración del reino de Dios [...] Esta persecución liene dos momentos distintos. El primero de ellos es el de aquella violencia estructural que hace a las mayorías pobres, las empobrece, en razón del mismo conjunto de acciones que hace ricos a sectores minoritarios; este momento de persecución es el momento de violencia y de pecado que hace injusticia al pueblo, pero al mismo tiempo hace que el pueblo se convierta en término preferencial de la misericordia y del cuidado divinos, constituyéndose así inicialmente en pueblo de Dios. El segundo momento de la persecución es el que surge como respuesla a acciones que las mayorías populares toman en su camino de liberación y que son frenadas violentamente por quienes buscan su condición privilegiada de dominio y explotación. Cuando se cometen acciones continuadas y sistemáticas contra los movimientos de liberación de quienes luchan por salir de su opresión para alcanzar la libertad que Dios quiere para todos los hombres y especialmente para los más débiles, nos encontramos con una estricta persecución por causa del reino de Dios ${ }^{16}$.

Sin duda que éste es un texto que podría analizarse más a fondo con provecho. Aquí interesa subrayar la distinción entre la persecución que expresa la muerte infringida por el mero hecho de existir y la desencadenada a modo de amenazas, lorturas y asesinatos como represión y respuesta a los que quieren expulsar esa violencia radical, a los que desean construir la justicia y la libertad. Esta segunda persecución culmina en lo que sería el "martirio por el reino de Dios", mientras que la primera da carne al martirio radical, o por nombrarlo de alguna manera, al "martirio crístico", es decir, el que padecen los desechados y deshechos de nuestro mundo, que han sido creados por Dios en Cristo y para Cristo (Col 1, 15-20). Al arrebalarles todo a las criaturas, sobre todo al arrebatarles la vida, continúa la pasión de Cristo en ellas. Sean o no creyentes, pertenezcan o no a la religión cristiana, en su mera condición humana - podríamos decir ontológica- las mayorías son imagen de Jesucristo, pues han sido creadas en El y por El. Son parte del pueblo de Dios, quien, al revelar escandalosamente su presencia en ellas y a través de su inmerecido dolor, declara que le pertenecen (1Pe 2, 10 ), que sus vidas no han sido abandonadas a su suerte y a su desgracia.

\subsection{El martirio por el reino de Dios}

No es mi intención forzar los textos de Ellacuría, y por eso he calificado de

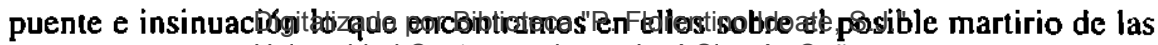
Universidad Centroamericana José Simeón Cañas

16. «Pueblo de Dios». Conceptos fundamentales de pastoral, pp. 853-854. 
mayorías. Pero en el segundo texto hay más que insinuación: es lo que ha dado en llamarse el "martirio por el reino de Dios". Desde la acepción usual de martirio, sin embargo, resulta extraño hablar de "martirio por el reino" -y mucho más extraño resulta hablar de "martirio crístico". Por ello es necesario explicar el concepto.

Tal como sintetiza Karl Rahner el significado tradicional de martirio, éste "designa el hecho de aceptar morir por la fe de forma libre y resignada, no luchando activamente como en el caso de los soldados"1". Esto quiere decir que, en rigor, no cualquier muerte - por muy desgarradora y cruel que nos parezca o que de hecho sea- es una muerte martirial. Se suponen algunos requisilos: que sea una muerte consciente, sufrida por libre asentimiento, y no en una lucha armada, en favor de la fe cristiana. Se trata de una vida y una muerte configuradas con la vida y la muerte de Cristo. Como dice Semmelroth, mártir es "el que se deja quitar la vida para afirmar la persona del Dios encarnado, reconocida por la fe, sufre la muerte in odium fidei"l . Martirio propiamente hablando, en la acepción clásica, es "martirio por la fe".

Sin embargo, desde hace algunos años, desde diversos lugares y a distintos niveles de la reflexión teológica se viene afirmando la necesidad de ampliar esa concepción clásica del martirio. Desde la exégesis blblica, Coenen ${ }^{19}$ ha demostrado que brindar testimonio martirial es algo más amplio que el "bautismo de sangre". Ser testigos fidedignos de Jesucristo para el mismo Nuevo Testamento es algo más abarcador que lo que posteriormente recogerá la acepción usual de martirio, acepción establecida históricamente. La figura del mártir, en efecto, se fue delimitando a través del devenir y los avatares de la fe cristiana, tal como ha probado Baumeister ${ }^{20}$. Los derroteros de esa misma fe, por lo tanto, pueden estar exigiéndonos replantear esa figura no para difuminarla, sino para ensancharla, y ello para hacer justicia no tanto a la figura misma cuanto a la riqueza interior que anlda en la propia fe cristiana. El propio Karl Rahner al final de su vida propuso y justificó teológicamente esa ampliación en la riqueza de la verdad de la fe y llega a preguntar: "¿por qué no habría de ser mártir un monseñor Romero, por ejemplo, caído en la lucha por la justicia en la sociedad, en una lucha que él hizo desde sus más profundas convicciones cristianas?"'! Y, como monseñor Romero, han sido millares de creyentes, en diversas partes del mundo,

17. K. Rahner, «Dimensiones del martirio», p. 321.

18. O. Semmelroth, «Martirio», c. 457.

19. Cfr. L. Coenen, «Testimonio», en Diccionario teológico del Nuevo Testamenıo IV (Salamanca, 1984) 254-261.

20. Cfr. Th. Baumeister, «Mártires y perseguidos en el cristianismo perseguido», Concilium 183 (1983) 312-320.

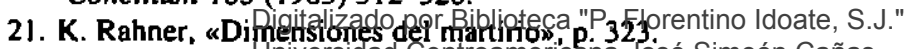


los que han sido asesinados por afirmar la fe y sus múltiples valores, tales como la libertad, la justicia, la paz, la solidaridad, la reconciliación, etc. ${ }^{22}$.

Estos son los "nuevos mártires", como afirma Manuel de Unciti". Desde la experiencia martirial de América Latina se ha propuesto, desde hace ya varios años, englobarlos como "mártires por el reino de Dios"24. Ser mártir por el reino de Dios no se ciñe a cristianos explícitos, sino que podría incluir a hombres y mujeres que han vivido y muerto, no siendo confesionalmente cristianos, pero con una vida y una muerte similares a la de Jesús (los "cristianos anónimos", según la conocida frase de Rahner), ambas orientadas y dirigidas por la búsqueda y el establecimiento del reino.

Ahora bien, ¿qué significa ser perseguidos y martirizados por el reino? ¿Qué elementos son inherentes a esa persecución y a ese martirio? Ellacuría sugiere al menos tres: "ser contra los más pobres y oprimidos a los que Dios ha prometido preferencialmente una salvación liberadora; ser resultado de quienes son responsables del orden injusto y de la estructura de pecado que domina en una determinada sociedad; y ser contra la marcha hacia el reino como lugar histórico en el que todos los hombres disfruten solidariamente de los recursos de la lierra y en el que las relaciones sociales y personales sean las queridas por Dios para los hombres".... Una marcha impulsada con mucho esfuerzo, tesón y sacrificio por pobres y por no pobres, por cristianos y por no cristianos, por creyentes en otras religiones y por quienes no se confiesan creyentes.

Y no sólo los teólogos han subrayado la novedad actual del martirio. El propio papa Juan Pablo II, en el número 37 de su carta Tertio millennio adveniente, ha señalado que esa oleada martirial constatable en este siglo $\mathrm{XX}$ que culmina es uno de los más importantes signos de los tiempos, una señal inequívoca de la presencia de Dios en nuestra actual historia; y que ese testimonio martirial no debe ser olvidado, sino todo lo contrario. Apoyados en él, los cristianos debemos abrirnos con fe y esperanza al milenio que se acerca. Para el análisis de ese texto remito al breve y espléndido comentario de Pié-Ninot ${ }^{26}$.

22. Cfr. Leonardo Boff, «Reflexión sistemática sobre el martirio», Concilium 183 (1983) 325-334.

23. Cfr. Manuel de Unciti, “Los nuevos mártires». Sal Terrae. Tomo 85/2 (1997) 165173.

24. Cfr. Jon Sobrino, «De una teología sólo de la liberación a una teología del martirion, en Cambio social y pensamiento cristiano en América Latina (Madrid 1993) 101-121; Ibíd., Jesucristo liberador (Madrid 1991) 334-342.

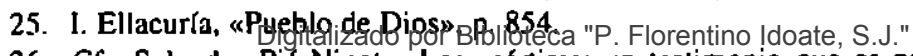

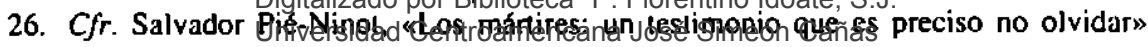
(Salamanca, 1995) 179-193. 


\subsection{El martirio crístico}

Una última aclaración. Necesario y razonable es ampliar el "martirio por la fe" con el "martirio por el reino de Dios". ¿Pero qué decir de lo que hemos llamado "martirio crístico" o martirio de las mayorías?

Retomemos algo que ya nos recordó en 1991 Jon Sobrino: la condición análoga del martirio ${ }^{27}$. Es decir, el martirio se dice de varias maneras. Así como Aristóteles dijo que el ser se dice de muchas formas (como roca, como planta, como color, como sonido, como persona, etc.), y así como todos sabemos y experimentamos que el amor se manifiesta con múltiples rostros (como amistad, como paternidad, como fratemidad, como solidaridad, como enamoramiento, etc.), así también puede ocurrir con el hecho martirial. Sus variados tipos —aquí estamos afirmando la existencia de al menos tres- hace que no tienen por qué reunirse en uno solo de ellos todos los rasgos de un martirio propiamente cristiano.

El papa Juan Pablo nos ayuda a concretar lo que sería lo particular y específico del martirio de los desechados. En su última encíclica $F e$ y razón, afirma que mártir "es el testigo más auténtico de la verdad sobre la existencia" (32c). Lo propio de todo testigo, de todo mártir, es sacar a la luz - desvelar- la verdad de lo que nos ocurre en nuestro vivir cotidiano y la verdad de lo que podemos buscar, construir y esperar juntos. En este sentido, los mártires por la fe o por el reino de Dios son aquellos que con su vida y con su muerte testimonian que la existencia auténtica, la vida perenne y eterna, se alcanza en ese misterio y esa paradoja que consiste en aquella palabra del Señor: "quien se reserve la vida la perderá y quien la ofrezca la encontrará". Son los mártires que reproducen la persona y la causa de Jesús. Son los testigos que participan de la muerte redentora de Jesucristo por la vía del seguimiento, de la reproducción e imitación. En cambio, los pueblos mártires, esas mayorías enfrascadas en situaciones de muerte que no la han buscado ni tampoco la merecen, testimoniarían, no por seguimiento, sino por continuación y representación, la verdad de lo que nos está ocurriendo, desnudan el anti-evangelio, la raíz y malicia del pecado. Si los primeros testimonian la genuinidad de la buena noticia, los segundos -en su dolor silencioso, en sus incontables padecimientos- testimonian su radicalidad y urgencia.

En cuanto testigos, los vencidos de la historia descubren ante todos nosotros el contenido, la malicia y la fealdad del pecado. Los destrozados y machacados nuestran en carne viva que pecar consiste en articular y vertebrar nuestra manera de vivir en base a un esquema que nos arroja y nos mantiene sumergidos en las garras del mal. Es el esquema vital de tener que crucificar a otros para poder

27. Cfr. Jon Sobringighalizado pgribibliateca "P E Elorentino Idoate, S.J." 
alcanzar y garantizar el propio bienestar, la proclividad a negar y destruir a otros para la propia y egoísta autoafirmación. Una autoafirmación que rompe la amistad con Dios, que fractura la convivencia con los seres humanos, lomándola injusta y cruel, y que entabla una batalla depredadora con la naturaleza, negando la armonía que debiera existir entre ella y la humanidad. Por esta razón, puede sostenerse que el martirio de las mayorías es el martirio radical, por sacar a luz pública la raíz de todos nuestros males y de todas nuestras desventuras.

$\mathrm{Y}$ no sólo eso. Al poner en evidencia el camino de muerte en que nos hemos embarcado, los testigos enmudecidos posibilitan que rehagamos lo que está mal hecho. No sólo alteran nuestras vidas llamándonos a la conversión, al cambio sincero y lirme, sino que nos concretan hacia dónde hay que caminar y el cómo hacerlo: a eliminar todo lo que en nuestro interior, en nuestra convivencia social y en nuestros proyectos históricos conduce al envilecimiento, a la deshumanización, a la idolatría. El clamor del martirio de las mayorías nos propone una exigencia nueva, la de convertimos a la amistad con Dios, a la justicia para con los hombres y al respeto para con la naturaleza, como camino ineludible para recibir y extender la salvación a todos los ámbitos de nuesıras vidas.

Asomándonos a los pasajes del Nuevo Testamento, podemos encontrar en el relato de la matanza de los inocentes por parte de Herodes (Mt 2, 16-18) la clave biblica que iluminaría el martirio de las mayorías. Es un episodio brevemente relatado, pero rico en matices. Ya sabemos que el evangelista Mateo está interesado en mostrar que en la persona, la vida y la muerte de Jesús de Nazaret, se han cumplido las promesas de Dios a su pueblo Israel. Un pueblo que rápidamente lo rechazó como el mesías esperado, y, al hacerlo, provoca su autoaniquilación: "al rechazar a Jesús y perseguirlo, Israel se autodestruye; no hace falta que vengan los tiranos desde fuera. El tirano está muy dentro. Es el rey, los sacerdotes, los escribas que no quieren ir al Cristo y que pretenden destruirlo"28. Israel es hoy la humanidad entera. Toda ella, a la par que anhela y busca su salvación - llámesela felicidad, liberación, humanizacion, plenitud, etc. - rechaza al auténtico portador, se repliega sobre sí, pretende ella misma definir y conquistar la salvación. He ahf el nudo central del pecado. Al volverse hacia sf misma, se embarca en la autodestrucción.

Esta autodestrucción queda simbolizada en el dar muerte cruel e injusta a esos niños que no han hecho nada para merecerla. No han optado por seguir a Jesús, ni por pro-seguir su causa. Simplemente son criaturas indefensas, que han sido anrojadas a un mundo donde el poder, el engaño y la maldad predominan y buscan extirpar de rafz y eliminar sin contemplaciones cualquier posibilidad de que el evangelio, la buena noticia, acceda a nuestras vidas y haga de nuestro

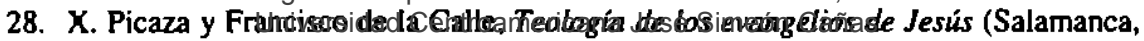
1974) 133. 
mundo su morada. Es lo que, a su vez, simboliza el pueblo crucificado. En él se encuentra condensada la autonegación de la humanidad a ser una única familia y un único pueblo de Dios.

Tampoco esa masa de humanidad doliente es perseguida por confesarse cristiana o por intentar realizar el reino de Dios. Simplemente incomoda y estorba su propia existencia. Se la desprecia, se la estima como indigna de todo. Y es una humanidad que, al igual que esos niños, sufre inocentemente. No olvidemos que, ya desde el antiguo cristianismo, se debatió si el sufrimiento de esos pequeños era o no culpable ${ }^{29}$. En el debate se abrí paso la certeza de que no eran culpables de nada, que su sufrimiento era inocente. Más aún, Cipriano y Rabano los presentaron como modelo diáfano e indiscutible de martirio.

Los padecimientos del pueblo crucificado poseen esa inocencia o, al menos, se acercan mucho a ella. Hay que aclarar de qué clase de inocencia se trata. Su inocencia no es jurídica - no se trata de que los crucificados no cometan delilos-, ni moral - tampoco se trata de que sean o no pecadores, pues sobran evidencias de que también lo son-, sino que es una inocencia teologal. Ser inocentes de esta manera significa que ellos son fruto del amor creador de Dios y son llamados a ser sus hijos (martirio crístico), son invilados a formar parte de su pueblo y a disfrutar con otros de las promesas que le ha hecho. Y son elegidos por él, en su pasión y en su muerte (continuadoras de la suya) para alcanzarnos la salvación. El martirio de las mayorías crucificadas, pisoteadas, humilladas y abandonadas, es el martirio de la inocencia. Nada más, pero tampoco nada menos.

29. Cfr. Ulrich Luz, El evangelio según san Mateo (Mt /-7), vol. I, (Salamanca, 1993) 172-185. 